The Bangladesh Veterinarian (2012) 29(1) : 17 - 21

\title{
Chromosomal analysis of Breeding bulls using lymphocyte culture
}

\author{
D. J. Patel, A. J. Patel, R. K. Patel ${ }^{*}$ and P. R. Parekh
}

Ashok and Rita Patel Institute of Integrated Study and Research in Biotechnology and Allied Sciences, New Vallabh Vidyanagar-388 121, Gujarat, India

\begin{abstract}
Chromosomal aberrations or abnormal karyotypes could be one reason for reproductive failure in breeding bulls. The objective of the study was to detect chromosomal abnormalities and their relation with fertility problem in cattle and water buffalo breeding bulls. Blood samples were collected from 30 buffalo bulls and 23 Holstein or Holstein-Friesian cross bred bulls for lymphocyte culture. No gross chromosomal abnormality was detected. However, a few samples exhibited polyploidy, premature centromeric division, chromosomal fragmentation, aneuploid cells, fragile site, chromatid gaps or breaks. These aberrations were not consistent feature in a particular animal; therefore, the aberrations may not have obvious effects on fertility. However, such aberrations should be scored in regular screening as a high percentage of such abnormalities can be associated with reduced fertility. (Bangl. vet. 2012. Vol. 29, No. 1, $17-21)$
\end{abstract}

\section{Introduction}

Most of the developments in domestic animal cytogenetics were achieved from human cytogenetics. Animal cytogenetics has several applications in animal improvement and one of these is to diagnose genetic abnormalities especially chromosomal aberrations that are usually associated with subfertility, infertility, embryonic losses and still births. Chromosomal abnormalities account for substantial loss in animal production and some pedigree bulls selected for breeding are subfertile or infertile (Alam and Hurtado, 1982). Many countries now screen bulls for chromosomal aberrations (Kovacs and Szepeshelyi, 1987; Patel, 2000). The most common effect of unbalanced karyotype is early embryonic mortality. Where artificial insemination ( $\mathrm{Al}$ ) is used, chromosomal aberration can be transmitted to large populations and it can cause repeat breeding in females because of embryonic losses, and poor semen quality in bulls. Cytogenetics in domestic animals was started in the early sixties and various abnormalities have been reported in Indian cattle (Prakash et al., 1995; Patel et al., 1997a; Patel, 1999a; Patel and Patel, 2000; Yadav, 2000; Patel, 2002 Patel, 2003; Muralidharan et al., 2011) and in buffaloes (Balakrishnan and Yadav 1984; Balakrishnan et al., 1985; Yadav et al., 1987; Yadav et al., 1990; Prakash et al., 1992; Prakash et al., 1994; Vijh et al., 1994; Patel et al., 1997; Patel and Khoda, 1998; Patel, 1999b; Patel et al., 2006; Chauhan et al., 2009; Prakash and Singh, 2009).

*Corresponding author:- E-mail: rkpatel46@yahoo.com 


\section{Materials and Methods}

A total of 53 heparinized blood samples were collected from 23 phenotypically normal Holstein-Friesian (HF) and HF Crossbred bulls and 30 Murrah buffalo bulls stationed at sperm stations of Gujarat State, India Chromosomal preparations were performed using standard whole blood culture in RPMI-1640 medium supplemented with antibiotics, $15 \%$ fetal calf serum and 1\% pokeweed mitogen (Patel et al., 1995). The culture was incubated at $37^{\circ} \mathrm{C}$ for 72 hours. To increase the relative frequency of prometaphase chromosomes, Ethidium bromide (Sigma, India) $10 \mu \mathrm{g} / \mathrm{mL}$ was added for two hours and to arrest somatic cell division at metaphase stage, colchicine (Sigma, India) $2 \mu \mathrm{g} / \mathrm{mL}$ was added for one hour. The cells were harvested by centrifugation at $1000 \mathrm{rpm}$ for five minutes followed by hypotonic treatment with $0.56 \% \mathrm{KCl}$ for 20 minutes at $37^{\circ} \mathrm{C}$ and fixed in $3: 1$ ratio of methanol and glacial acetic acid. Finally, cell suspension was dropped on slides and air dried. Slides were stained with Giemsa stain for screening under the Nikon (Japan) compound microscope with photographic system.

\section{Results and Discussion}

Cattle (Bos taurus) normally possess 60 (2n) chromosomes, 29 pairs of autosomes and one pair of sex chromosomes. All the autosomes are acrocentric and sex chromosomes (XY) are submetacentric. The water buffalo (Bubalus bubalis) possesses 50 (diploid) chromosomes, 24 pairs of autosomes and one pair of sex chromosomes. The first five pairs of autosomes are submetacentric, whereas all others including sex chromosomes are acrocentric. The $\mathrm{X}$ chromosome is largest acrocentric, and can be easily identified even without GTG banding. The Y chromosome is among the smaller acrocentric chromosomes (Kumar and Yadav, 1991) and can be identified by conventional $\mathrm{G}$ and $\mathrm{C}$-bandings.

In most samples, approximately 30 metaphase chromosome fields were screened. No breeding bull exhibited gross abnormalities except for some sporadic chromosomal aberrations like polyploidy (Fig. 1), premature centromeric division (PCD; Fig. 2), chromosomal fragmentation (Fig. 3), aneuploid cells (Fig. 4), fragile site (Fig. 5), chromatid gaps or breaks. These low degrees of aberrations were not consistent for a particular sample, therefore, may not have obvious effects on fertility. However, such aberrations should be scored, as a high percentage of such abnormalities can be associated with reduced fertility (Prasanthi et al., 2004; Sangamitra et al., 2004; Patel et al., 2011), which is generally not noticed as fertility of bulls is not regularly monitored in many countries. 


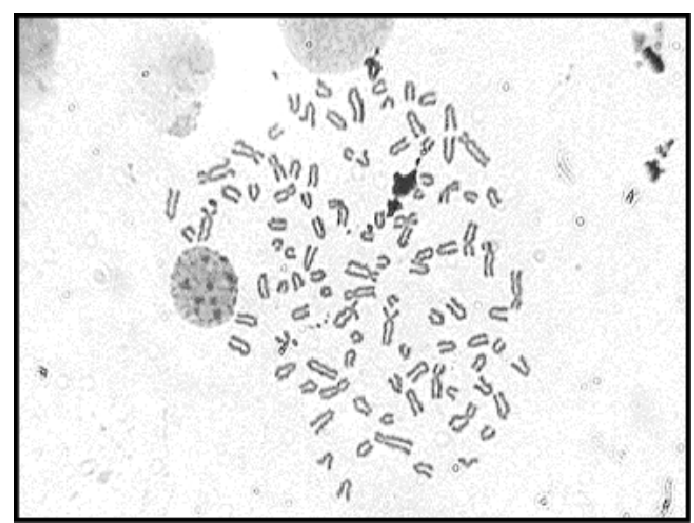

Fig. 1. Polyploidy cell of Buffalo

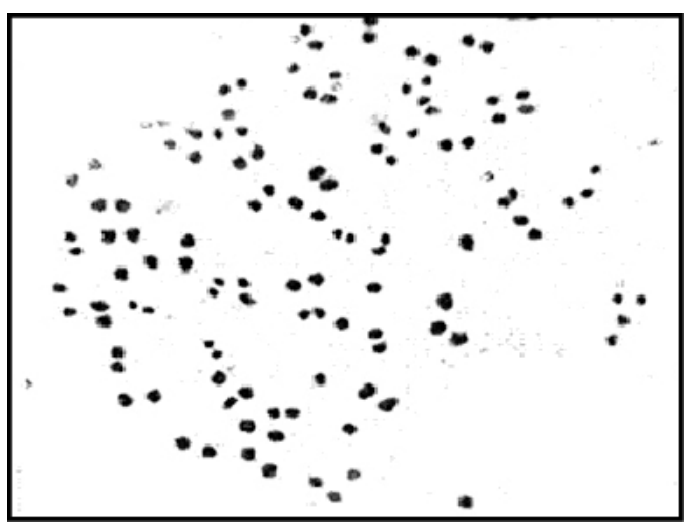

Fig. 3. Chromosomal fragmentation in cattle

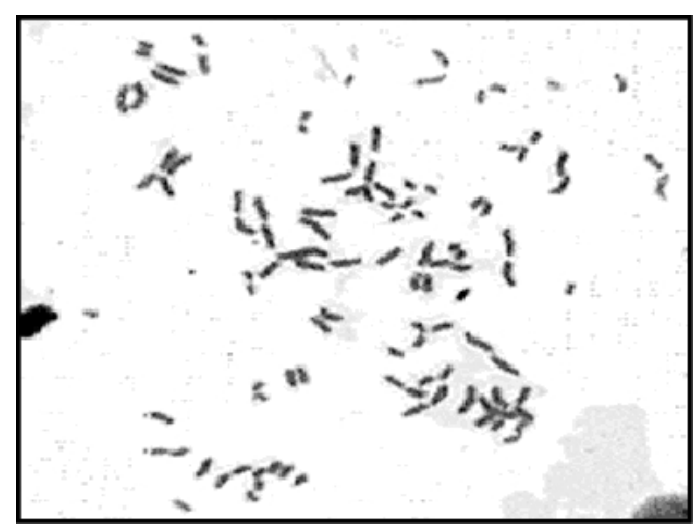

Fig. 2. PCD in cattle chromosomes

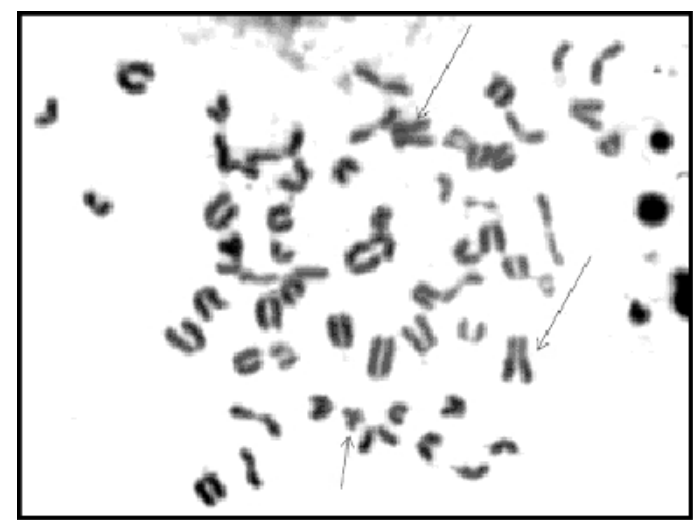

Fig. 4. Aneuploid cell $(61, \mathrm{XXY})$ of cattle. Large arrows indicate $X$ chromosome and small arrow indicates $\mathrm{Y}$ chromosome

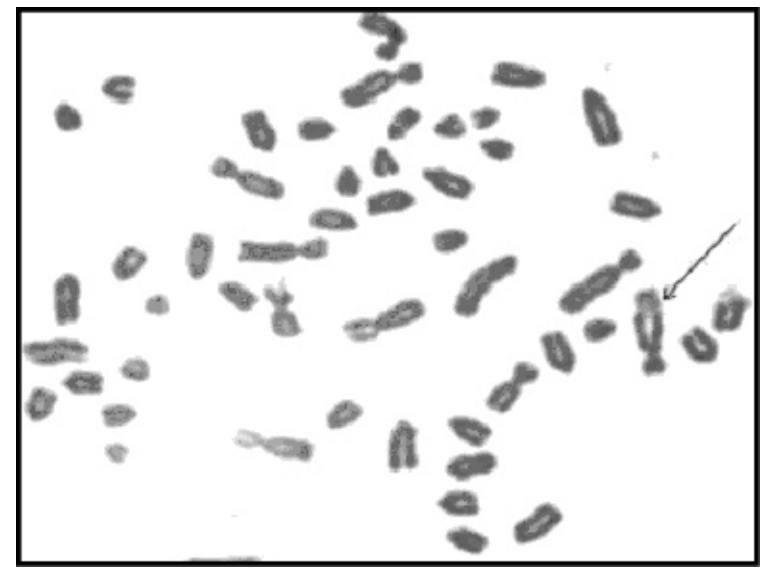

Fig. 5. Arrow indicates fragile chromosome in buffalo 


\section{Acknowledgements}

Authors are highly thankful to the Ashok and Rita Patel Institute of Integrated Study and Research in Biotechnology and Allied Sciences and the Charutar Vidyamandal for providing research facilities. We are also thankful to the Ode farm of AMUL Dairy for providing samples.

\section{Reference}

Alam MGS, Hurtado R 1982: Testicular hypoplasia syndrome due to chromosomal aberration (Trisomy 61/XXY). Indian Journal of Veterinary Medicine 2 55-60.

Balakrishnan CR, Yadav BR 1984: Normal and abnormal chromosomes in the Indian River buffalo bull. Buffalo bulletin 3 13-17.

Balakrishnan CR, Yadav BR, Yadav JS 1985: Spontaneous paracentric inversion in Indian buffalo. Nucleus 28 45-48.

Chauhan JB, Patel RK, Singh KM, Soni KJ 2009: Impact of a novel Cytogenetic finding (unusual $\mathrm{X} ; \mathrm{X}$ translocation) on fertility of a buffalo bull (Bubalus bubalis). Buffalo Bulletin 28 151-153.

Kovacs A, Szepeshelyi F 1987: Chromosomal screening of breeding bulls in Hungary. Journal of Dairy Science 70 (Suppl) 136.

Kumar P, Yadav BR 1991: Comparative cytogenetical study in Mehsana, Murrah and Surti buffaloes. Indian Journal of Dairy Science 44 157-161.

Muralidharan P, Reddy C, Jain N, Reddy SK, Patel RK 2011: A Case of Centric Fusion Translocation in a Deoni (Bos indicus) Indian cattle bull calf. IIOAB Journal 2 21-23.

Patel RK 1999a: A new case of Robertsonian translocation rob $(7 ; 16)$ in HF crossbred bull. Indian Journal of Dairy Science 52 324-329.

Patel RK 1999b. Presence of an unusual secondary constriction in smallest autosome of subfertile Murrah buffalo bull (Bubalus bubalis). Buffalo Newsletter (FAO) 12 4-7.

Patel RK 2000: Karyotyping of dairy animals. Andhra Pradesh Veterinarian 3 24-26.

Patel RK 2002: Sex chromosomal aneuploidy $(61$, XXY) in a Jersey calf. Indian Journal of Veterinary Research 11 21-23.

Patel RK 2003: Sex chromosome mosaicism (60, XX/61, XXX) in an infertile HF heifer. Indian Journal of Animal Reproduction 24 161-162.

Patel RK, Khoda VK 1998: Presence of Variant chromosome 3 in the infertile water buffaloes (Bubalus bubalis). Veterinary Review 13 25-27.

Patel RK, Patel SM 2000: A 61, XXY chromosome complement in subfertile Jersey crossbred bull. Indian Journal Animal Reproduction 21 68-69.

Patel RK, Radhakrishna U, Khoda VK 1997a: Unusual silent blood chimerism in HolsteinFriesian bull. Indian Journal Animal Science 67 152-153. 
Patel RK, Radhakrishna U, Khoda VK 1997b: Mitotic disturbance associated with variant chromosome 3 in river buffalo bulls (Bubalus bubalis). Buffalo Journal 2 173-178.

Patel RK, Singh KM, Soni KJ 2005: Sex chromosomal aneuploidy (61, XXY) in HolsteinFriesian and Kankrej crossbred calf: A Case Report. Haryana Veterinarian 44 75-76.

Patel RK, Singh KM, Soni KJ, Chauhan JB 2006: Novel cytogenetics finding: Unusual translocation X:X in Mehsana Buffalo (Bubalus bubalis). Cytogenetics and Genome Research 115 186-188.

Patel VA, Patel RK, Shah PB, Parikh PA 2011: Cytogenetic studies of the dairy bulls. Wayamba Journal of Animal Science Article No. 1320750403.

Prakash B, Singh DS 2009: First case of centric fission in Murrah buffalo bull. Journal of Livestock Biodiversity 1 56-57.

Prakash B, Balain DS, Laathwal SS, Malik RK 1994: Trisomy X in a sterile river buffalo Veterinary Record 134 241-242.

Prakash B, Balain DS, Lathwal SS, Malik RK 1995: Infertility associated with monosomy-X in a crossbred cattle heifer. Veterinary Record 137 436-437.

Prakash B, Balin DS, Lathwal SS 1992: A 49, XO sterile Murrah buffalo (Bubalus bubalis). Veterinary Record 130 559-560.

Prasanthi GS, Patel RK, Sambasiva Rao KRS, Singh KM 2004: Detection of fragile site on chromosomes of sub-fertile cattle bulls. Intas Polivet 5 87-93.

Sangamitra K, Patel RK, Sambasiva Rao KRS, Singh KM 2004: Initial study on detection of fragile site on chromosomes of sub-fertile Murrah buffalo bulls. Haryana Veterinarian 48 71-74.

Vijh RK, Tanita MS, Sahai R 1994: Translocation in Murrah buffalo. Indian Journal of Animal Science 64 534-538.

Patel VA, Patel RK, Shah PB, Parikh PA 2011: Cytogenetic studies of the dairy bulls. Wayamba Journal of Animal Science Article No. 1320750403.

Yadav BR 2000: Autosomal trisomy in zebu calf (Sahiwal breed of cattle). Journal of Cytogenetics and Genetics $\mathbf{7 1} 76$.

Yadav BR, Balalkrishnan CR, Tomar OS 1987: Multiple births in bubalus bubalis (Murrah Buffaloes): Cytogenetic investigations. Indian Journal of Animal Research 8 107-112.

Yadav BR, Kumar P, Tomar OS, Kumar S, Balin DS 1990: Monosomy -X and Gonadal dysgenesis in buffalo Heifer. Theriogenology 3490. 